\title{
Assessment of muscle fiber adaptation in footballers using a new ELISA assay of myosin isoforms
}

\author{
Mario GUERRERO 1, Gerard CARMONA 2, Gil RODAS 3, Joan A. CADEFAU 1, 2, \\ Antonio MAESTRO ${ }^{4}$, Roser CUSSÓ 1,5 *
}

\begin{abstract}
${ }^{1}$ Department of Biomedecine, Faculty of Medicine, University of Barcelona, Barcelona, Spain; ${ }^{2}$ INEF of Catalunya, Barcelona, Spain; ${ }^{3}$ Futbol Club Barcelona, Barcelona, Spain; ${ }^{4}$ Real Sporting Club Gijón, Gijón, Spain; 5 Institut d'Investigacions Biomèdiques (IDIBAPS), University of Barcelona, Barcelona, Spain

*Corresponding author: Roser Cussó, Department of Biomedecine, Faculty of Medicine, University of Barcelona, c/ Casanova 143. 08036, Barcelona, Spain.
\end{abstract} E-mail:mcusso@ub.edu

\section{A B S T R A C T}

BACKGROUND: To measure the impact of training models on injury incidence, data of health and performance were integrated to study fiber adaptation during a competitive season. We studied football players over a season, analyzing hours of exposure to sport by serum changes in fast and slow myosin, creatine kinase and lactate dehydrogenase.

METHODS: A new assay was developed to measure the myosin isoforms in 49 non-sporting volunteers and in 27 professional football players. RESULTS: Myosin isoforms in volunteers with mean ages of $30 \pm 8$ were $1553 \mu \mathrm{g} / \mathrm{L}$ fast and $1284 \mu \mathrm{g} / \mathrm{L}$ slow; in the group with of $56 \pm 7$ were $1426 \mu \mathrm{g} / \mathrm{L}$ fast and $1046 \mu \mathrm{g} / \mathrm{L}$ slow. Slow myosin was significantly lower in older subjects $(-18 \%)$. Samples from the players in preseason had lower mean scores for fast myosin $(1123 \mu \mathrm{g} / \mathrm{L})$ and higher for slow myosin $(2072 \mu \mathrm{g} / \mathrm{L})$ than reference volunteers. During the season, myosins reached the maximum with the maximum load $(1537 \mu \mathrm{g} / \mathrm{L}$ fast, $2195 \mu \mathrm{g} / \mathrm{L}$ slow but decreased and adapted to the high level of demand $(425 \mu \mathrm{g} / \mathrm{L}$ fast, $1342 \mu \mathrm{g} / \mathrm{L}$ slow). CK and LDH were maximal at the pre-season $(227 \mathrm{U} / \mathrm{L}, 333 \mathrm{U} / \mathrm{L})$ while myosin levels were maximal at the beginning of season $(1537 \mu \mathrm{g} / \mathrm{L}, 2195 \mu \mathrm{g} / \mathrm{L})$.

CONCLUSIONS: Measuring serum myosin isoforms we identify the type and amount of damage caused by training and matches, making it a new control tool capable of advising training towards a minimum of blood slow myosin but controlling the fast fiber participating and be able to improve the performance of the players.

(Cite this article as: Guerrero M, Carmona G, Rodas G, Cadefau JA, Maestro A, Cussó R. Assessment of muscle fiber adaptation in footballers using a new ELISA assay of myosin isoforms. J Sports Med Phys Fitness 2019;59:000-000. DOI: 10.23736/S0022-4707.19.09463-5)

KEY wORDS: Myosins; Football; Enzyme-Linked Immunosorbent Assay.

$\mathrm{P}$ rofessional football schedules are characterized by a high frequency of competitive matches in which each outfield player covers a mean distance of $10-12 \mathrm{~km}$. To get the good efficiency they combine low speed walking/ running displacements with short-term high-intensity running and sprinting that can exceed $23 \mathrm{~km} \cdot \mathrm{h}^{-1} .^{1}$ The most frequent injuries occur ankle, knee and hamstring. ${ }^{2-4}$

In the pre-season, rectus femoral strains injuries $(29 \%)$ are more frequent than biceps femoral injuries incidence (11\%), composition (47, 1\% fiber type I and 52, 4\% fiber type II) 5 but during the season, the risk of injury to posterior thigh muscles is higher. 3,6 Overall, hamstring muscle injuries are the most prevalent, accounting for $12-16 \%$ of all injuries. ${ }^{7}$ The fiber structural damage can be produced by the collisions and the metabolic stress from prolonged high-intensity exercise that contribute to tissue damages in the players. Hamstrings muscle fiber composition may be predominantly fast-twitch ${ }^{8}$ and could explain the high incidence of hamstrings strain injuries. ${ }^{5}$ However, our understanding of hamstrings fiber morphology (size and composition) and how this relates to contractile function is relatively limited. Since the human muscles all have a composition in fast and slow fibers, relatively similar in composition, ${ }^{9}$ but not in their function, it is very important to know the fiber 
status of the whole team and the individually players during training and competitions in order to schedule them.

Professional football teams apply biochemical monitoring extensively. However, traditional blood analysis only provides limited information about physical muscle strain and overload, or about acute muscular response and adaptation to exercise and injury. Creatine kinase (CK) as very well know muscle marker helps to understand the mechanism of fatigue and health status. ${ }^{10}$ Meyer and Meister ${ }^{11}$ and Nédélec et al. ${ }^{12}$ assessed a good role of CK as a biochemical marker of muscle response to football training and competition. They are not fiber-specific; although their levels are higher in type II fibers. ${ }^{13}$ In general, they cannot be associated with either fiber type ${ }^{14}$ but help us to know the normal or damaged state of the fibers. Normal people without any injuries detected by ultrasonography and magnetic resonance showed serum CK around $102 \pm 8$ U/L. When damage was not determined neither by ultrasonography nor by magnetic resonance but it was classified as Grade I the CK corresponded to $202 \pm 22$ U/L. Grade II and III show higher $\mathrm{CK}$ in serum. ${ }^{15}$ Lactate dehydrogenase (LDH) behaves similarly to $\mathrm{CK}$, but it has not proven to be a better marker than CK.

Guerrero et al. ${ }^{15}$ have demonstrated the use of fast and slow myosin as markers of injury. These myosin isoforms are ideal for studying the grade of fiber injury because fast myosin is characteristic of fast muscle fibers only and slow myosin is specific to slow and cardiac muscle fibers..$^{15}$ Sorichter et al. ${ }^{16}$ described that myosin (slow isoform) was present in serum from one to nine days after induced injury. Guerrero et al. ${ }^{15}$ successfully applied a Western blot technique for the assessment of fast and slow myosin isoforms in sportsmen who suffered skeletal muscle injuries detected by ultrasound and/or magnetic resonance. They show that the use of myosins as muscle marker was particularly valuable and sensitive for diagnosing grade I muscle injuries, which are usually difficult to diagnose through magnetic resonance and ultrasound, because mild injuries were mainly associated with fast-twitch fiber injuries. Later Carmona et al. ${ }^{17}$ have shown that fast myosin isoform increased in the serum after inertial concentric-eccentric exercise only, while mountain ultramarathon competitors showed a selective increase in the slow isoform. ${ }^{18}$ Consequently, it may be possible to use these markers to distinguish between injury in fast and slow fibers, and to classify muscle injuries by severity. Specifically, myosins may help identify mild (grade I) muscle injury (strain/contusion), as stated above, which reflect a tear of only a few fibers that is accompanied by discomfort, and a minimal loss of strength-generating capacity and restriction of movement. ${ }^{19}$ Because muscle injuries are the most prevalent in football, and because their prevention is a major challenge of sports medicine, ${ }^{20}$ myosins may prove to be very useful diagnostic tools for distinguishing the type and severity of injury. However, Western blot technique used until present is a slow assay, not very sensitive so their research was limited by the long time to obtain results to diagnose skeletal muscle injuries.

The aim of this study was to examine the changes in fast and slow myosin serum concentrations during a football season, using a new methodology able to get better results to help and optimize diagnose earlier. We hypothesized that the use of serum myosin isoforms as muscle markers would reflect the muscle's response and adaptation to training and competition more accurately than traditional biochemical markers. The usual use of these markers in the periodic medical check-ups during a competitive season can indicate whether the hours of exposure and the specificity of training contents should be modified. A previous and quick diagnosis, knowing the type of fibers affected can help the prognostic and evolution of a more important injury and advice on an action on the design of the training for each particular player.

\section{Materials and methods}

\section{Materials}

Monoclonal anti-myosin fast antibody (Sigma M1570); monoclonal anti-myosin slow antibody (Sigma M8421); Purified pork myosin (Sigma M0273); polyclonal rabbit antibody (Sigma M7523); Anti-anti rabbit antibody linked to peroxidase (Sigma A6154); superblock blocking buffer (Thermo Scientific 37515); Standard phosphate buffered saline, 10mM, pH 7.4 (PBS); tween 20 (Sigma P7949); TMB luminescent peroxidase substrate (Sigma T0440); polystyrene plate (Corning 3591) and Vacutainer ${ }^{\circledR}$ tubes (ref.: 367783). In addition, we used the following reagents: $\mathrm{K}_{2} \mathrm{HPO}_{4}$ (Merck 105104), $\mathrm{KH}_{2} \mathrm{PO}_{4}$ (Merck 4873), $\mathrm{NaCl}$ (Merck 106404), and $\mathrm{H}_{2} \mathrm{SO}_{4}$ (Merck 100731).

\section{Participants}

Forty-nine healthy volunteers ( 26 males and 23 females, (aged 20-66 years; mean age $44 \pm 14$ ) attending the Catalan Blood Donor Unit participated in the experiment and were the reference group to get normal results according the new method used. They did not practice any sport the two weeks before experiment. Their informed consent was obtained.

In addition, we enrolled 27 male professional football 
players (mean age, $24 \pm 4$ years; height, $179 \pm 6 \mathrm{~cm}$; weight, $74.8 \pm 6 \mathrm{~kg}$ ) from Sporting Gijon Club, a top-level Spanish league club. The football players were analyzed every two months at 6 predefined medical check-ups during a competitive season. All participants were informed of the nature of the programmer during the pre-season and all gave their consent to participate.

The Ethics Committee for Human Experiments of Gijon University and Barcelona University (Spain) approved the study and it was conducted in accordance with the Declaration of Helsinki.

\section{Methods}

\section{Samples}

For analysis, we obtained $2 \mathrm{~mL}$ of blood from participants. In the case of football players, blood was obtained in the pre-season and at different points during the season. Samples were obtained by standard venipuncture from the antecubital vein in a Vacutainer ${ }^{\circledR}$ tube and centrifuged at $2000 \times g$ at $4{ }^{\circ} \mathrm{C}$ for $10 \mathrm{~min}$ to obtain serum. The serum was then stored at $-80^{\circ} \mathrm{C}$ for later analysis.

Muscle fast and slow myosin assessment by enzyme-linked immunosorbent assay

Quantification by the enzyme-linked immunosorbent assay (ELISA) sandwich test was performed as follows. Monoclonal anti-myosin fast and slow antibodies (400 ng and $300 \mathrm{ng}$, respectively) were coated onto a polystyrene plate, dissolved in $100 \mu \mathrm{L}$ of PBS and stored overnight at $4^{\circ} \mathrm{C}$. Plates were then washed with PBS (added with $0.05 \%$ Tween 20; PBS wash) and blocked with Superblock during $1 \mathrm{~h}$ of incubation at $37^{\circ} \mathrm{C}$ on a stir plate. A second PBS wash was performed.

The calibration curve was performed with six different concentrations of purified pork myosin, containing both fast and slow myosin dissolved in control human serum diluted in PBS (1/11). The six concentration points were between $0 \mathrm{ng}$ and $250 \mathrm{ng}$ of myosin protein. ${ }^{21}$ We loaded $10 \mu \mathrm{L}$ of each serum sample into plate wells in triplicate, and the plates were incubated and stirred at $37{ }^{\circ} \mathrm{C}$ for 1 hour and washed three times with PBS.

To close the sandwich ELISA, the polyclonal rabbit antibody (1/500 diluted in superblock blocking buffer) was added, and the mix was incubated while stirring for $1 \mathrm{~h}$ at $37{ }^{\circ} \mathrm{C}$. Plates were then washed three times with PBS and incubated with an anti-anti rabbit antibody linked to peroxidase (1/500 dilution in Superblock blocking), and then stirred for $1 \mathrm{~h}$ at $37^{\circ} \mathrm{C}$. Plates were washed again three times with PBS and incubated at room temperature with $50 \mu \mathrm{L}$ of TMB substrate for the luminescent reaction of the peroxidase. After 7-10 min the reaction was stopped with $50 \mu \mathrm{L}$ of $2 \mathrm{M} \mathrm{H}_{2} \mathrm{SO}_{4}$, and the plates were placed on a Synergy 2 reader $\left(\right.$ Biotek $\left.^{\circledR}\right)$ to measure the absorbance of each well at a wavelength of $450 \mathrm{nM}$. Microsoft Excel carried out data processing. Purified myosin used as standard had a composition of $50 \%$ of fast myosin and $50 \%$ of slow myosin, ${ }^{22}$ since it has a similar typology to human muscle.

Recovery was not calculated because recovery tests are used to determine whether assays are affected by the difference between the diluent used to prepare the standard curve and the sample matrix. In our case, the diluent used to prepare the standard curve was a serum that had been previously analyzed, and for which we knew the original myosin content.

Other blood biochemical analysis

$\mathrm{CK}$ and lactate dehydrogenase (LDH) were analyzed by an ADVIA Chemistry 2400 analyzer (Siemens Healthcare Diagnostics, Tarrytown, US), according to the manufacturer's instructions.

\section{Hours of exposure}

Total hours of exposure were measured during the preseason (defined as the period between player's holidays and the start of official competitions). During this period, training usually occurs in which new players are evaluated and techniques and strategies are tested. Then, we measured the total hours of exposure during the season (official competition period). Each value was analyzed and expressed as the sum of training sessions and match hours completed.

The training season was subdivided into 3 large macrocycles. The first macrocycle was in the first three weeks with an ATR (accumulation-transformation-realization) design and the second and third macrocycles through a classic periodization. The total sessions were 9. Each session included aerobic exercises, mobilization, stretching and technical exercises with the ball. There was speed work with the ball and specific exercises for each player position (anaerobic gestures).

\section{Statistical analysis}

Data are expressed as means \pm standard deviations. The distribution of each variable was analyzed by the ShapiroWilk test. Values of CK and LDH twice the mean value (approximately $400 \mathrm{U} / \mathrm{L}$ ) were excluded, because the study 
sought to compare how the hours of exposure related to serum biochemical indicators under conditions in which injury was not suspected. After excluding these values, 5.7\% of the study data were eliminated, and the data samples for $\mathrm{LDH}$ and $\mathrm{CK}$ met the requirements of a normal distribution according to the Shapiro-Wilk test. For variables that did not comply were assessed using Student's $t$-tests. Oneway repeated measure analysis of variance was performed after analyzing the effect of time on workload in relation to the serum markers (fast and slow myosin, $\mathrm{LDH}$ and $\mathrm{CK}$ ). When a significant main effect was detected, comparisons were performed using paired $t$-tests with Bonferroni correction. Correlation between variables was also assessed by the Pearson correlation test. Effect sizes (ES) and 90\% confidence intervals (lower limit:upper limit) were calculated to assess the difference between 2 group means. Threshold for ES values were 0.2, trivial; 0.6, small; 1.2, moderate; 2.0 , large; 4.0 , very large; and $>4.0$, extremely large. ${ }^{23}$ All statistical analyses were conducted using IBM SPSS, Version 22.0 (IBM Corp., Armonk, NY, USA).

\section{Results}

The characteristics of the ELISA calibration curves were prepared with pork myosin. The slope average for the calibration curve was measured with 20 repetitions, giving results of $0.0029 \pm 0.001$ for slow myosin and $0.0016 \pm 0.0004$ for fast myosin. The correlation index ( $\mathrm{r}$ ) was near maximal for both slow $\left(\mathrm{r}^{2}=0.99\right)$ and fast $\left(\mathrm{r}^{2}=0.98\right)$ myosin. The calibration curve showed a very good linearity $(80 \%$ for fast myosin and $90 \%$ for slow myosin). The intra-assay coefficient of yariation (CV \%) was assayed using three different samples (low, medium and high) and measured 12 times each. The $\mathrm{CV}$ was below $11 \%$ for fast myosin and below $6 \%$ for slow myosin.

The reference values for the reference population of healthy blood donors are shown in Figure 1. Fast and slow myosins were determined in the blood of adult volunteers and were balanced in terms of age and sex. These results permitted further comparisons with the results obtained in the study of myosin isoforms in the serum of the football players. The study met the requirements of normality, resulting in the mean fast and slow myosin values: for the group aged 20-44 years (young group), the values were 1553 and $1284 \mu \mathrm{g} / \mathrm{L}$ serum, respectively; and for the group aged 45-66 year (older group) the values were 1426 and $1046 \mu \mathrm{g} / \mathrm{L}$, respectively. Slow myosin levels were significantly lower in older subjects $(-18.5 \%, \mathrm{P}<0.05)$.

The total hours of player's exposure (training plus

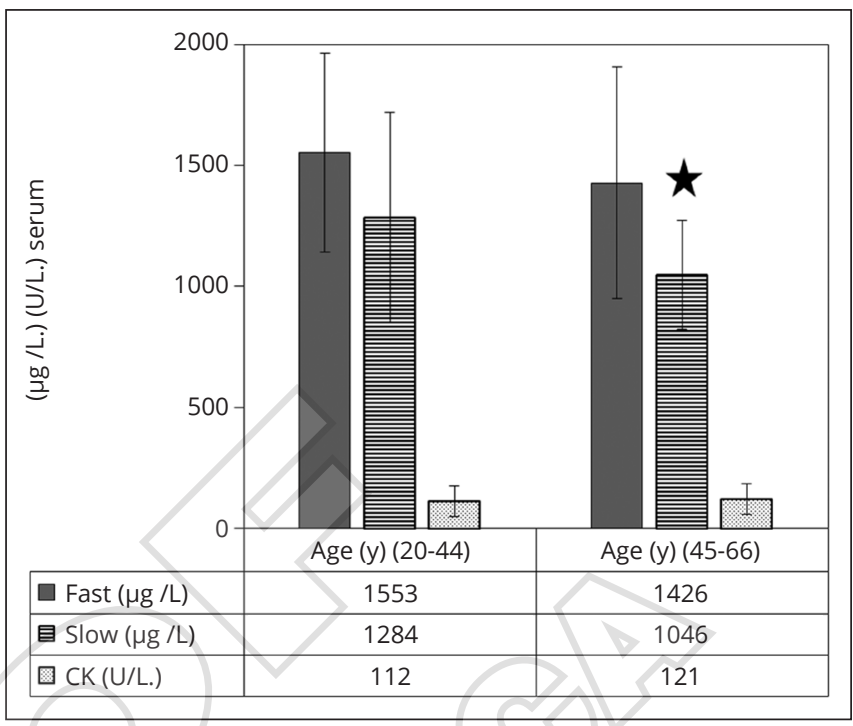

Figure 1. Fast and slow myosin values in the reference population. The results are means \pm SD. Fast and slow myosin are expressed as $\mu \mathrm{g} / \mathrm{L}$ serum. $\mathrm{CK}$ is expressed as $\mathrm{U} / \mathrm{L}$ serum (CK activity). The black symbol indicates statistical significance $(\mathrm{P}<0.05)$.

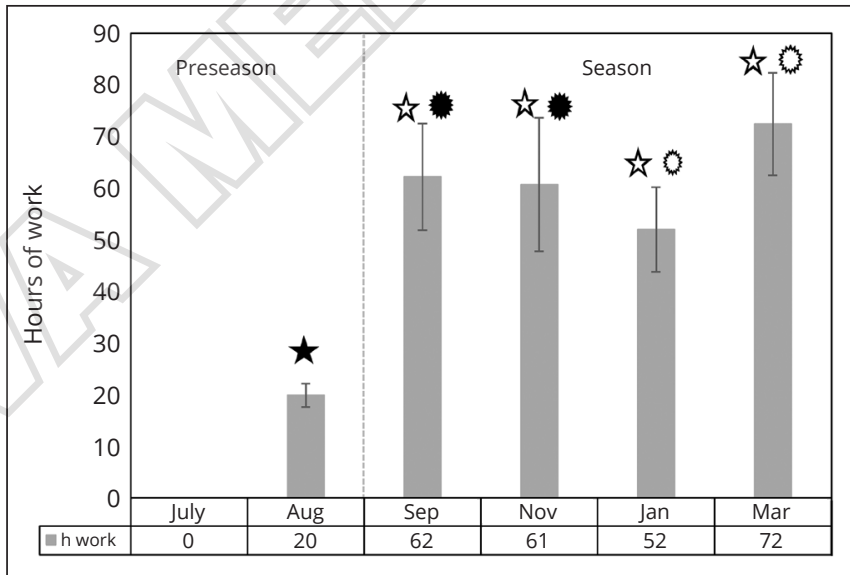

Figure 2.- Hours of exposure per time period analyzed. They are expressed as training plus match hours (mean $\pm \mathrm{SD}$ ). The dashed line indicates the end of pre-season and the beginning of the season. The white symbols indicate statistical significance $(\mathrm{P}<0.05)$ compared with black symbols.

match hours analyzed) are shown in Figure 2. In the preseason, players were exposed to around $20 \mathrm{~h}$ of training and competitive play per month, and 52 to $72 \mathrm{~h}$ per month during the season $(\mathrm{P}<0.001)$. There were significant differences between hours of exposure during the season, particularly for the break at Christmas and the break at the end of the season.

The evolution of myosin markers during the pre-season 
TABLE I.-Levels of serum muscle markers during pre-season and season.

\begin{tabular}{|c|c|c|c|c|c|c|}
\hline & \multicolumn{2}{|c|}{ Preseason } & \multicolumn{4}{|c|}{ Season } \\
\hline & July & August & September & November & January & March \\
\hline Fast myosin & $1123 a \pm 594$ & $600 a * b \pm 379$ & $1537 \mathrm{~b} * * \mathrm{c} \pm 899$ & $784 c^{*} \pm 42$ & $494 \mathrm{c} * * \pm 283$ & $425 \mathrm{c}^{* *} \pm 220$ \\
\hline $\mathrm{ES}(95 \% \mathrm{CI})$ & & $-0.87(-1.43--0.32)$ & $0.18(0.35-0.72)$ & $-0.72(-1.28--0.17)$ & $-1.21(-1.80--0.63)$ & $-1.34(-1.94--0.74)$ \\
\hline Slow myosin & $2072 \mathrm{~d} \pm 1018$ & $1719 \mathrm{e} \pm 925$ & $2195 \mathrm{e}^{* \mathrm{f}} \pm 939$ & $1973 \pm 1010$ & $1097 \mathrm{~d} * * \mathrm{f} * * \pm 572$ & $1342 \pm 854$ \\
\hline $\mathrm{ES}(95 \% \mathrm{CI})$ & & $-0.36(-0.90-0.17)$ & $-0.04(-0.57-0.50)$ & $-0.4(-0.94-0.14)$ & $-1.12(-1.70--0.54)$ & $-0.96(-1.53--0.39)$ \\
\hline CK & $156 \mathrm{~g} \pm 66$ & $227 \mathrm{~g} * \mathrm{~h} \pm 94$ & $173 \pm 79$ & $204 \pm 61$ & $169 \pm 87$ & $153 \mathrm{~h} * \pm 67$ \\
\hline ES $(95 \% \mathrm{CI})$ & & $0.81(0.26-1.36)$ & $0.65(0.10-1.20)$ & $0.53(-0.01-1.08)$ & $0.70(0.15-1.26)$ & $0.43(-0.13-0.97)$ \\
\hline $\mathrm{LDH}$ & $296 \mathrm{i} \pm 41$ & $333 \mathrm{i}^{* *} \pm 36$ & $318 \pm 38$ & $\left.331 i^{*} \pm 40\right)$ & $319 \pm 41$ & $307 \pm 47$ \\
\hline ES $(95 \% \mathrm{CI})$ & & $0.96(0.40-1.52)$ & $0.57(0.01-1.10)$ & $0.86(0.31-1.42)$ & $0.56(0.01-1.11)$ & $0.25(-0.31-0.81)$ \\
\hline
\end{tabular}

Data are expressed: myosin as $\mu \mathrm{g}$ of myosin/L of serum; CK and LDH as: Units /L of serum; \pm SD.

ES: effect size; CI: confidence intervals.

Mean values with unlike letters were significantly different $(\mathrm{P}<0.05)$

*statistical significance $(\mathrm{P}<0.05)$ and $* *$ statistical significance $(\mathrm{P}<0.01)$

and the official season is shown in Table I. Fast myosin concentration in serum decreased significantly in the first weeks of the pre-season, from July to August (-46.6\%, $\mathrm{P}=0.02)$, but it increased significantly at the beginning of the competitive season, from August to September $(+61 \%, \mathrm{P}=0.01 * *)$. The comparison of fast myosin from September's to November, fell by $49 \%(\mathrm{P}=0.02 *)$, to January $68 \%(\mathrm{P}=0.01 * *)$, and to March $72 \%(\mathrm{P}=0.01 * *)$. Slow myosin showed a similar pattern. Slow myosin fall significantly during the competitive season from July to January $(-47 \%, \mathrm{P}=0.01 * *)$, and there are significant differences between August and September $(-36 \%, \mathrm{P}=0.033 *)$ and September and January $\left(-50 \%, \mathrm{P}=0.008^{* *}\right)$. Clear decreases were observed in both fast and slow myosin serum concentrations during the season, when the hours of exposure stabilized, rose, or fell only slightly. Significant differences were found in mean CK levels in the pre-season, between July and August $(+49 \%, \mathrm{P}<0.05)$ and in the transition from pre-season to the season from $\mathrm{Au}-$ gust to March; $(-34 \%, \mathrm{P}=0.05)$, but eventually returned to the baseline values. Significant differences in LDH were found in the pre-season $(+14 \%, \mathrm{P}<0.001)$ and between July and November $(+12 \%, P=0.04)$, but, the values returned to baseline.

TABLE II.-Fast and slow myosin values, and their ratio.

\begin{tabular}{lccc}
\hline Participants & Fast & Slow & Fast:Slow \\
\hline Younger group & $1553 \pm 411$ & $1284 \pm 434$ & 1.21 \\
Older group & $1426 \pm 479$ & $1046 \pm 225$ & 1.36 \\
ES & 0.38 & 0.71 & \\
$(95 \%$ CI $)$ & $(-0.85-0.28)$ & $(-1.29--0.13)$ & \\
Football team July & $1123 \pm 594$ & $2072 \pm 1018$ & 0.54 \\
Football team September & $1537 \pm 899$ & $2195 \pm 939$ & 0.70 \\
Football team January & $494 \pm 283$ & $1097 \pm 572$ & 0.45 \\
\hline
\end{tabular}

Data are expressed: myosin as $\mu \mathrm{g}$ of myosin/L of serum; \pm SD.
Table II shows the fast/slow myosin ratios for the reference and football players groups. In the reference groups (volunteers), the ratio was 1.21 for young subjects and 1.36 for older subjects. Among the football players, it was around 0.5 at the beginning of the pre-season and rose to 0.7 when exposure increased significantly in September.

\section{Discussion}

Compared with myosin analysis by Western blot, the ELISA shortened the time to obtain results from 48 to 4 hours. The ELISA method also allowed the processing of 26 samples in triplicate at the same time, making it much more economical than Western blot and more suitable for periodic testing of football players and other sports players. Moreover, the method we tested had very good sensitivity and reproducibility. To the best of our knowledge, this is the first study to use ELISA to quantify fast and slow myosin isoforms in the sera of players from an entire professional football team, and to determine whether this relates hours of exposure to training or playing.

The reference group showed no differences in sex or age for fast myosin, but there were significant differences in the slow myosin isoform between age of the younger (20-44 years) and older (45-66 years) volunteer's groups. The loss of slow fibers may be either due to the more sedentary lifestyles or to a loss of slow muscle fibers in the older group.

Comparing the results of the football players with the reference population, football players had lower mean scores for fast myosin and higher mean scores for slow myosin. Fast:slow myosin ratio reflected these differences, which was always lower than that in the reference young 
population (ratio 1.21) among players (ratios 0.54, 0.70, $0.45)$. These data may indicate that training and competitive matches enhance the performance of aerobic fibers.

Individually, none of the players who had higher myosin values at the beginning of the season had higher values in the following controls, indicating that any minor damage they may have sustained early on did not progress (results not shown).

Analysis of fast and slow myosins in the pre-season (during training in August) showed that there was no damage of the sarcomere structure in any fiber type. By contrast, at the beginning of season when tactical and/or physical training started both fiber types were damaged to different extents, as indicated by the fast: slow ratio. When the hours of exposure increased at the beginning of the season (September), the fast fibers suffered more damage than the slow fibers, with the highest fast and slow myosin values coinciding with the start of the season and the peak hours of exposure. This may indicate the presence of muscle damage that dissociates sarcomere proteins involved in contraction. Thereafter, levels of both myosin isoforms decreased significantly despite the same exposure, indicating an adaptation of the muscles to training and competition. The moderate correlation between the two-myosin markers indicates that the mechanism of damage on the sarcomere structure is the same in both types of fiber of football players in that performance.

CK and LDH, both very well-known biochemical muscle markers, were analyzed at different points during the competitive season and pre-season. During pre-season (August) activities of both CK and LDH increased significantly, indicating that the cytoplasmic membrane was damaged at that time (Table I). By the end of the season, however, $\mathrm{CK}$ and $\mathrm{LDH}$ activities returned to baseline. The high moderate correlation between CK and LDH could indicate that both markers appear in the blood at the same time in the pre-season and season, and are the first serum markers to appear when muscle workload begins. They show an onset of myofibrillar disruption and an inflammatory process located in the fiber membrane before the sarcomere disruption.

The use of cytoplasmic enzymes (CK and LDH) and sarcomere proteins (myosins) as markers of muscle fiber damage may help understand the different stages of a competitive season associated with increased hours of exposure. In the first stage, the cell membrane damage leads to the release cytoplasmic low molecular weight proteins (CK, LDH) into the blood. In the second stage, if the demand continues to increase, the sarcomere structure then begins to break down, releasing myosin into the blood. This is important because the increase in membrane permeability is easily recoverable, but disorganization of the sarcomere, if persistent, leads to fatigue, which is recovered only after more than 3 days of rest. ${ }^{24}$

The Clinical Practice Guide 25 recommend the use of myosin isoforms as markers of fiber damage in. This adds a new tool for training and adjustment programmers to improve the efficiency of physical preparation for competition in football and other sports. ${ }^{26}$ Our new ELISA technique for measuring myosin isoforms as markers of incipient injury is the easiest and quickest way to detect early modifications in sarcomere structure in fast and slow fibers. Sarcomere disorganization is a first signal of muscle fatigue and to detect it could help avoid the deterioration of damage during a competitive season. If used appropriately, it could identify the impact of training and competitive matches on each type of fiber, helping to control the degree of damage and avoid injury progression to grades 2 or 3, which can sideline players during the season.

In turn, this can prevent sports losses and improve the efficiency of the sports club. The use of this measurement in medical check-ups during the competitive season can help personal training and improve performance in any sport.

In practice the measurement of serum myosins will help us detect a start of fatigue in the course of training. It would be unnecessary to use it when more important injures are already observed, which are easily detected by other methods.

Our results show that the Gijón team followed a very convenient training to minimize damage but at the same time they show it could improve their training design to get better results in their league competition.

\section{Limitations of the study}

A limitation of our methodology is that the extent of damage or injury affecting muscle fibers takes between 24 and 48 hours to appear in the serum, delaying diagnosis. However, the stability of myosin in serum allows analysis of damage after more than a week.

\section{Conclusions}

ELISA technique easily measures myosin isoforms in serum and indicate muscle fiber damage by hours of exposure. Their use allows practitioners to identify the type and amount of muscle fiber damaged based on the type and intensity of sports training and matches. Therefore, it may be a reliable control tool for trainers and medical staff. 


\section{References}

1. Di Salvo V, Baron R, Tschan H, Calderon Montero FJ, Bachl N, Pigozzi F. Performance characteristics according to playing position in elite soccer. Int J Sports Med 2007;28:222-7.

2. Fuller CW, Junge A, Dvorak J. Risk management: FIFA's approach for protecting the health of football players. Br J Sports Med 2012;46:11-7.

3. Ekstrand J, Hägglund M, Waldén M. Injury incidence and injury patterns in professional football: the UEFA injury study. Br J Sports Med 2011;45:553-8.

4. Inklaar H. Soccer injuries. I: incidence and severity. Sports Med 1994;18:55-73

5. Evangelidis PE, Massey GJ, Ferguson RA, Wheeler PC, Pain MT, Folland JP. The functional significance of hamstrings composition: is it really a "fast" muscle group? Scand J Med Sci Sports 2017;27:1181-9.

6. Mendiguchia J, Garrues MA, Cronin JB, Contreras B, Los Arcos A, Malliaropoulos $\mathrm{N}$, et al. Nonuniform changes in MRI measurements of the thigh muscles after two hamstring strengthening exercises. J Strength Cond Res 2013;27:574-81.

7. Mendiguchia J, Samozino P, Martinez-Ruiz E, Brughelli M, Schmikli $\mathrm{S}$, Morin JB, et al. Progression of mechanical properties during on-field sprint running after returning to sports from a hamstring muscle injury in soccer players. Int J Sports Med 2014;35:690-5.

8. Garrett WE Jr, Califf JC, Bassett FH 3rd. Histochemical correlates of hamstring injuries. Am J Sports Med 1984;12:98-103.

9. Johnson MA, Polgar J, Weightman D, Appleton D. Data on the distribution of fibre types in thirty-six human muscles. An autopsy study. J Neurol Sci 1973;18:111-29.

10. Twist $\mathrm{C}$, Highton J. Monitoring fatigue and recovery in rugby league players. Int J Sports Physiol Perform 2013;8:467-74.

11. Meyer T, Meister S. Routine blood parameters in elite soccer players. Int J Sports Med 2011;32:875-81.

12. Nédélec M, McCall A, Carling C, Legall F, Berthoin S, Dupont G. Recovery in soccer: part I - post-match fatigue and time course of recovery. Sports Med 2012;42:997-1015.

13. Egan B, Zierath JR. Exercise metabolism and the molecular regulation of skeletal muscle adaptation. Cell Metab 2013;17:162-84.

14. Hecksteden A, Skorski S, Schwindling S, Hammes D, Pfeiffer
M, Kellmann M, et al. Blood-Borne Markers of Fatigue in Competitive Athletes - Results from Simulated Training Camps. PLoS One 2016;11:e0148810

15. Guerrero M, Guiu-Comadevall M, Cadefau JA, Parra J, Balius R, Estruch $\mathrm{A}$, et al. Fast and slow myosins as markers of muscle injury. $\mathrm{Br} \mathrm{J}$ Sports Med 2008;42:581-4, discussion 584 .

16. Sorichter S, Puschendorf B, Mair J. Skeletal muscle injury induced by eccentric muscle action: muscle proteins as markers of muscle fiber injury. Exerc Immunol Rev 1999;5:5-21.

17. Carmona G, Guerrero M, Cussó R, Padullés JM, Moras G, Lloret M, et al. Muscle enzyme and fiber type-specific sarcomere protein increases in serum after inertial concentric-eccentric exercise. Scand J Med Sci Sports 2015;25:e547-57.

18. Carmona G, Roca E, Guerrero M, Cussó R, Irurtia A, Nescolarde L, et al. Sarcomere Disruptions of Slow Fiber Resulting From Mountain Ultramarathon. Int J Sports Physiol Perform 2015;10:1041-7.

19. Järvinen TA, Järvinen TL, Kääriäinen $M$, Kalimo $H$, Järvinen $M$. Muscle injuries: biology and treatment. Am J Sports Med 2005;33:745-64.

20. Ekstrand J, Healy JC, Waldén M, Lee JC, English B, Hägglund M. Hamstring muscle injuries in professional football: the correlation of MRI findings with return to play. Br J Sports Med 2012;46:112-7.

21. Bradford MM. A rapid and sensitive method for the quantitation of microgram quantities of protein utilizing the principle of protein-dye binding. Anal Biochem 1976;72:248-54.

22. Lee SH, Choe JH, Choi YM, Jung KC, Rhee MS, Hong KC, et al. The influence of pork quality traits and muscle fiber characteristics on the eating quality of pork from various breeds. Meat Sci 2012;90:284-91.

23. Hopkins WG, Marshall SW, Batterham AM, Hanin J. Progressive statistics for studies in sports medicine and exercise science. Med Sci Sports Exerc 2009;41:3-13.

24. Frías JA, Cadefau JA, Prats C, Morán M, Megías A, Cussó R. Disturbances of the sarcoplasmic reticulum and transverse tubular system in 24-h electrostimulated fast-twitch skeletal muscle. Biochim Biophys Acta 2005;1668:64-74.

25. Rodas G, Pruna R, Til L, Martin C. Clinical Practice Guide for muscular injuries. Epidemiology, diagnosis, treatment and prevention. Apunts Med Espor 2009; 164:179-203.

26. Urhausen A, Kindermann W. Diagnosis of overtraining: what tools do we have? Sports Med 2002;32:95-102.

Conflicts of interest. - The authors certify that there is no conflict of interest with any financial organization regarding the material discussed in the manuscript. Funding.-This study was supported by the Ministerial de Ciencia e Innovation (PET2008 0224), MAPFRE Foundation (SV-07-MAPFRE-SALUD, Insti-

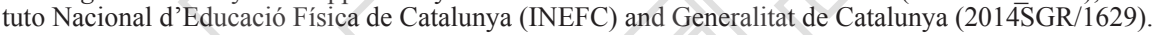

Manuscript accepted: March 19, 2019. - Manuscript revised: March 7, 2019. - Manuscript received: October 28, 2018. 